\title{
Age at Time of Vaccination
}

National Cancer Institute

\section{Source}

National Cancer Institute. Age at Time of Vaccination. NCI Thesaurus. Code C103173.

The age of the subject at the time of the vaccination. 